\title{
Potentiometric Determination of Copper in Herbal Material and Hydrolats of Veronica Species (Family Plantaginaceae)
}

\author{
Ante Prkic ${ }^{1, *}$, Ivana Mitar ${ }^{2}$, Josipa Giljanovic ${ }^{1}$, Marija Nazlić ${ }^{3}$, Dario Kremer ${ }^{4}$, \\ Ivana Anđelic ${ }^{2}$, Nenad Vuletić ${ }^{2}$, Valerija Dunkic ${ }^{3}$ \\ ${ }^{1}$ Department of Analytical Chemistry, Faculty of Chemistry and Technology, Ruđera Boškovića 35, \\ 21000 Split, Croatia. \\ ${ }^{2}$ Department of Chemistry, Faculty of Science, Ruđera Boškovića 33, 21000 Split, Croatia. \\ ${ }^{3}$ Department of Biology, Faculty of Science, Ruđera Boškovića 33, 21000 Split, Croatia. \\ ${ }^{4}$ Faculty of Pharmacy and Biochemistry, A. Kovačića 1, 10000 Zagreb, Croatia. \\ *E-Mail: prkic@ktf-split.hr.
}

doi: $10.20964 / 2018.12 .16$

Received: 20 July 2018 / Accepted: 18 Sepember 2018 / Published: 5 November 2018

\begin{abstract}
The aim of our work was an implementation of potentiometric determination of copper in samples of the genus Veronica (family Plantaginaceae). Genus Veronica herbs are widely used in e.g. cosmetic, traditional medicine and food industry. The copper content was potentiometrically analysed in 25 herbal samples of genus Veronica and 12 of their hydrolats. The analysed samples were herbal samples of Veronicas harvested mainly in three Croatian regions - Dalmatia, Lika and Slavonia as well as randomly selected samples of theirs hydrolats. Veronicas' samples were digested in a microwave oven by using nitric acid and hydrogen peroxide mixture. The potentiometric determination was performed by using commercially available CuISE for $\mathrm{Cu}^{2+}$, by using potentiometric methods previously developed in our laboratory.
\end{abstract}

Keywords: copper, genus Veronica, potentiometric determination, ion-selective electrode

\section{$\underline{\text { FULL TEXT }}$}

(C) 2018 The Authors. Published by ESG (www.electrochemsci.org). This article is an open access article distributed under the terms and conditions of the Creative Commons Attribution license (http://creativecommons.org/licenses/by/4.0/). 